\title{
Contact With Medical Risk Factor
}

National Cancer Institute

\section{Source}

National Cancer Institute. Contact With Medical Risk Factor. NCI Thesaurus. Code

C102611.

A way of contracting a disease by interacting with an individual that is considered at high risk for having the disease. 